\title{
Reversed halo sign in pneumocystis pneumonia: a case report
}

\author{
Hiroshi Otera ${ }^{{ }^{*}}$, Kimihide Tada ${ }^{1}$, Toshiyasu Sakurai ${ }^{1}$, Kimio Hashimoto $^{2}$, Akihiko Ikeda ${ }^{1}$
}

\begin{abstract}
Background: The reversed halo sign may sometimes be seen in patients with cryptogenic organizing pneumonia, but is rarely associated with other diseases.

Case presentation: We present a case study of a 32-year-old male patient with acquired immunodeficiency syndrome, who had previously been treated with chemotherapy for non-Hodgkin's lymphoma. A chest X-ray showed bilateral patchy infiltrates. High-resolution computed tomography revealed the reversed halo sign in both upper lobes. The patient was diagnosed with pneumocystis pneumonia, which was successfully treated with sulfamethoxazole trimethoprim; the reversed halo sign disappeared, leaving cystic lesions. Cases such as this one are rare, but show that the reversed halo sign may occur in patients who do not have cryptogenic organizing pneumonia.
\end{abstract}

Conclusion: Physicians can avoid making an incorrect diagnosis and prescribing the wrong treatment by carefully evaluating all clinical criteria rather than assuming that the reversed halo sign only occurs with cryptogenic organizing pneumonia.

\section{Background}

Pneumocystis pneumonia (PCP) is the most common serious respiratory complication found in patients with acquired immunodeficiency syndrome (AIDS) [1]. The typical radiographic features of PCP are bilateral perihilar distributions of ground-glass opacities (GGOs); however, a wide variety of radiographic findings have been observed [2-4]. The reversed halo sign is reported to be specifically associated with cryptogenic organizing pneumonia (COP) [5], but here we present the first case, to our knowledge, of PCP with a reversed halo sign.

\section{Case presentation}

A 32-year-old man was admitted to our hospital with an eight-week history of fever and productive cough. Approximately two years prior to presentation, extranodal B-cell non-Hodgkin's lymphoma (NHL) had been diagnosed, for which the patient had undergone chemotherapy. On admission, the patient's body temperature was $38.8^{\circ} \mathrm{C}$, blood pressure was $124 / 72 \mathrm{~mm} \mathrm{Hg}$, pulse

\footnotetext{
* Correspondence: h.ohtera@nmc-kobe.org

'Department of Respiratory Medicine, Nishi-Kobe Medical Center 5-7-1,

Kojidai, Nishi-ku, Kobe, 651-2273 Japan

Full list of author information is available at the end of the article
}

rate was 106 beats/min, and percutaneous oxygen saturation was $96 \%$ in room air. Physical examination revealed coarse crackles over the posterior right lung. The patient's white blood count was 5,500 cells $/ \mathrm{mm}^{3}$ (lymphocytes $=25 \%$, neutrophils $=55 \%$, and atypical $=8 \%$ ). CD4 cell count was 53 cells/ $\mu$ l and HIV-1 RNA count was $2.5 \times 10^{4}$ copies $/ \mathrm{ml}$. Chest radiography showed bilateral patchy infiltrates. A high-resolution computed tomography (HRCT) scan showed the reversed halo sign in the upper lobes and patchy parenchymal infiltrates in the lower lobes (Figure 1). A transbronchial lung biopsy was performed from the upper segmental bronchus. Histologically, the Grocott stain showed characteristic staining of many round structures surrounded by foamy, intraalveolar exudate and unaccompanied by interstitial pneumonitis (Figure 2).

The patient was diagnosed with PCP and AIDS. He was treated with sulfamethoxazole trimethoprim. The symptoms improved within 20 days, and chest radiography showed normal and chest CT showed remarkable improvements; the reversed halo sign disappeared, leaving cystic lesions (Figure 3).

C Biomed Central

(c) 2010 Otera et al; licensee BioMed Central Ltd. This is an Open Access article distributed under the terms of the Creative Commons Attribution License (http://creativecommons.org/licenses/by/2.0), which permits unrestricted use, distribution, and reproduction in any medium, provided the original work is properly cited. 

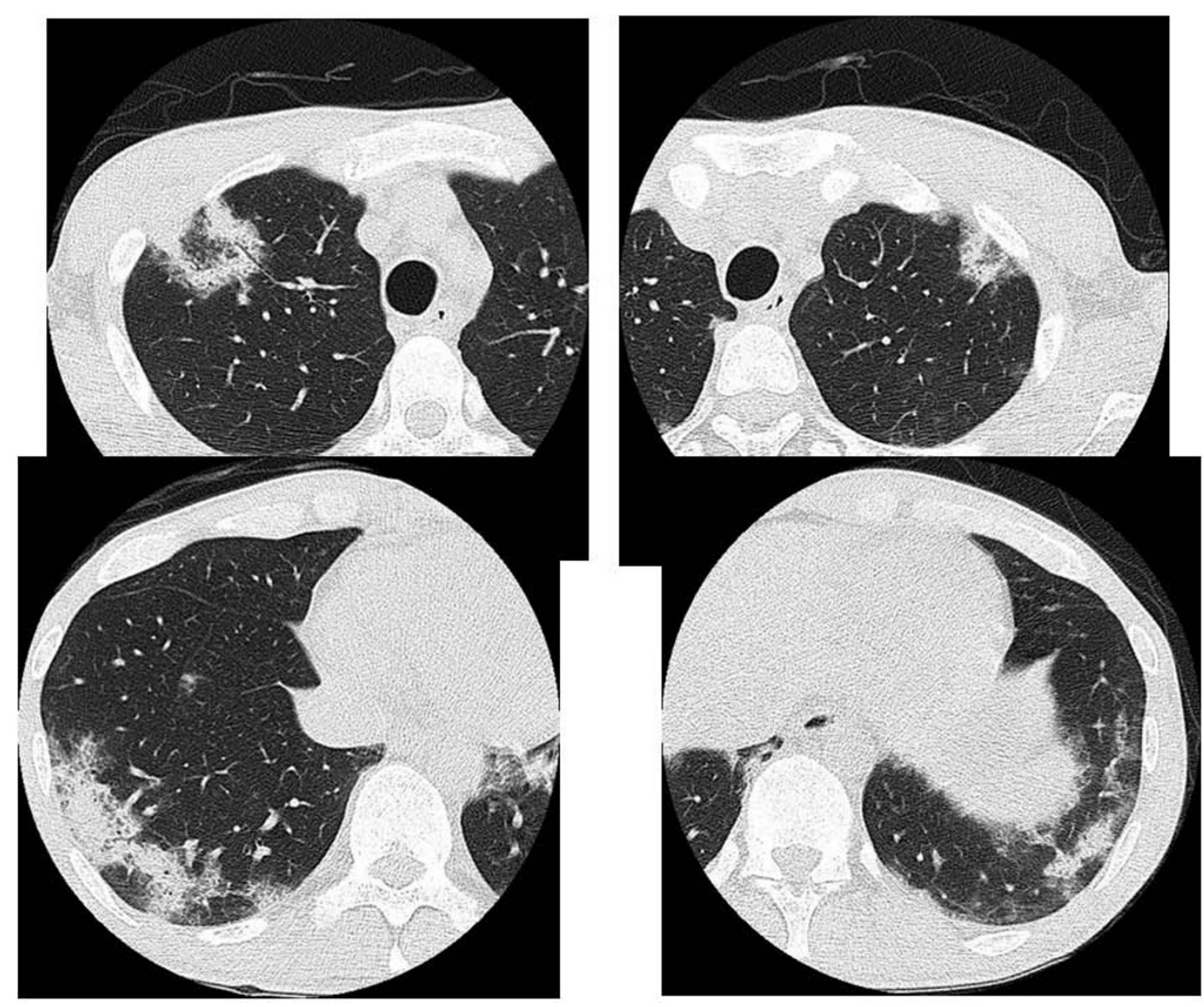

Figure 1 High-resolution computed tomography images of the lung before sulfamethoxazole trimethoprim treatment. The reversed halo signs and consolidations are shown.

\section{Discussion}

In 1996, Voloudaki et al. [6] reported two cases of COP that appeared on HRCT scans as central GGO surrounded by a denser air-space consolidation of crescent and ring shapes. This appearance was later named the "reversed halo sign" and defined as central GGO surrounded by a denser consolidation of crescentic (forming more than three-fourths of a circle) or ring (forming a complete circle) shapes that are at least $2 \mathrm{~mm}$ in thickness [5]. In studies of patients with COP, the reverse halo sign has been found in $12-19 \%$ of patients $[5,7]$ (Table 1). In fact, the reversed halo sign is so closely associated with COP that its presence is commonly used to make a diagnosis.

In Voloudaki's study of COP [6], the central GGO corresponded histopathologically to the area of alveolar septal inflammation and cellular debris; the ring-shaped or crescentic peripheral air-space consolidation corresponded to the area of organizing pneumonia within the alveolar ducts. The mechanism behind the reversed halo sign, in association with non-infectious diseases, has been likened to dropping a pebble into a pond: Inflammation occurs in the middle and spreads outward, while simultaneously improving at the site of occurrence. The changes in the center of the "pond" result in the GGO appearance [8].

The reversed halo sign has also been observed in association with other diseases, including the infectious diseases paracoccidioidomycosis (PCM), tuberculosis (TB), pulmonary zygomycosis, and pulmonary aspergillosis. In fungal infections, histology revealed that the lung was infarcted and had more hemorrhaging in the periphery than in the center [9]. However, in patients with PCM who underwent surgical lung biopsy, the central area of the lesions consisted of an inflammatory infiltrate in the alveolar septa, composed of macrophages, lymphocytes, plasma cells, and some giant cells, with relative preservation of the alveolar spaces [10]. The peripheries of the lesions consisted of dense and homogeneous intra-alveolar cellular infiltrates. There was no evidence of organizing 


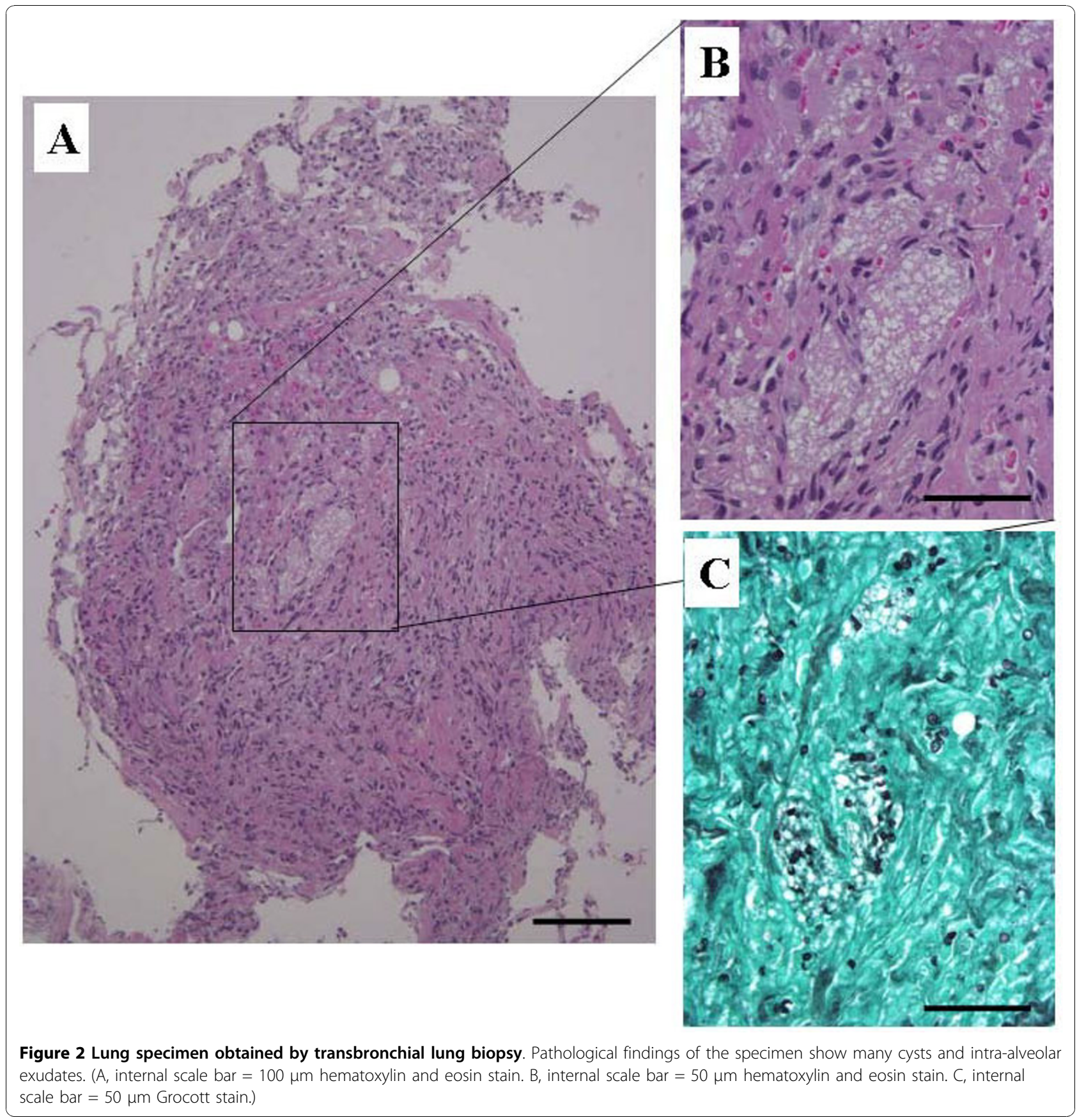

pneumonia or large hemorrhage. Grocott-Gomori methenamine-silver stain confirmed the presence of fungus (P. brasiliensis) in the alveolar septa and in the air spaces. In TB cases, pathology revealed the presence of caseating granulomas. The pathological findings for each infectious disease are distinct, greatly diminishing the chance of a misdiagnosis.

In humans, PCP is caused by infection with Pneumocystis jiroveci. This pathogen exists in two dominant forms: a cyst and a trophozoite. In humans, the trophozoite attaches itself to type 1 alveolar epithelial pneumocytes by way of interdigitation with the host cell membrane. This causes proteinaceous fluid to leak into the alveolar spaces. These spaces become filled with a characteristic "foamy" eosinophilic exudate that contains trophozoites, cysts, fibrin, and dead cells. Type 2 pneumocytes replicate in order to replace the damaged type 1 pneumocytes. This leads to mobilization of lung macrophages and plasma cells within the interstitium, causing a mild interstitial pneumonitis. Eventually, interstitial fibrosis develops as the lung tries to 

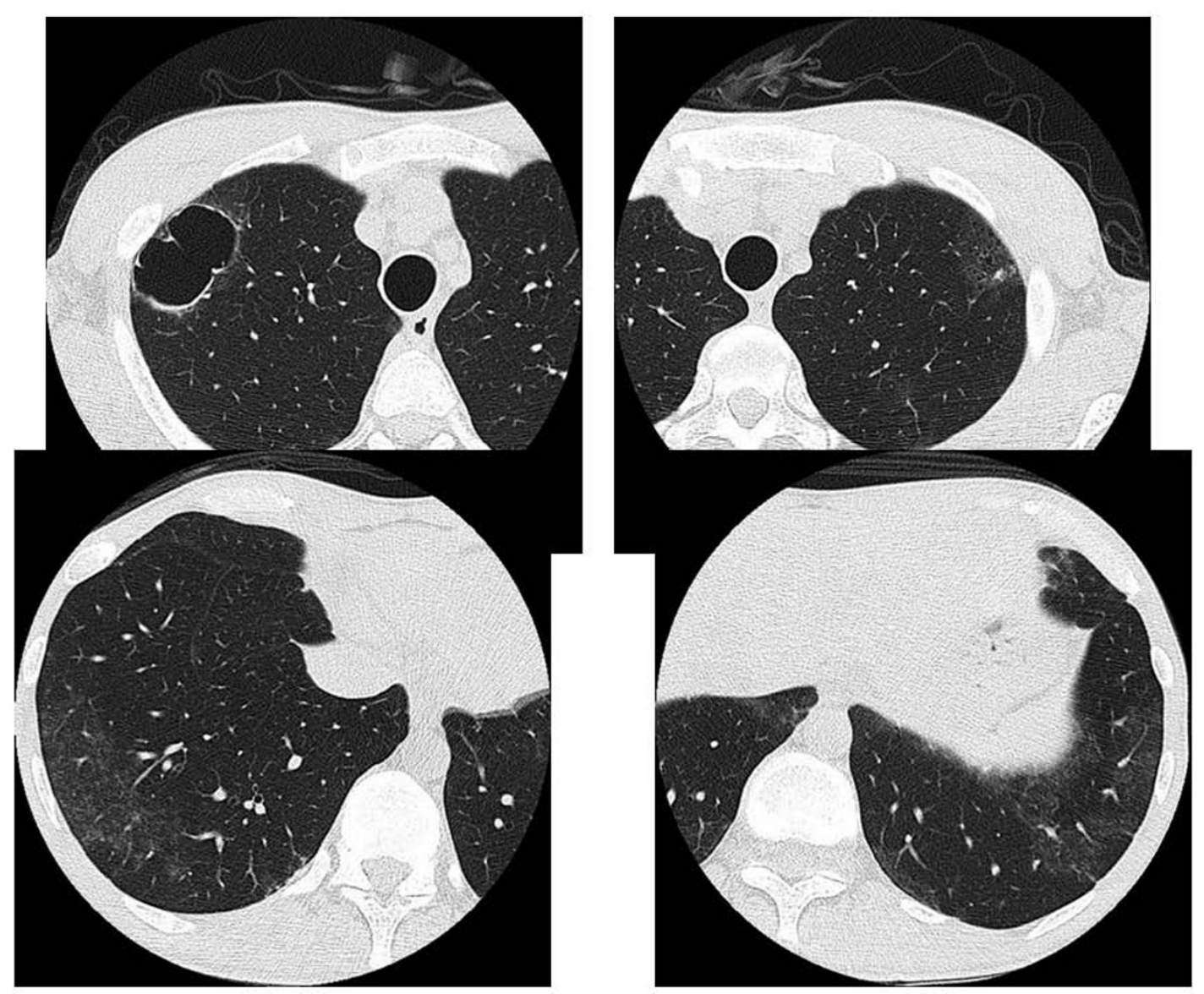

Figure 3 High-resolution computed tomography images of the lung 20 days after sulfamethoxazole trimethoprim treatment. Various sizes of cystic lesions are seen in the bilateral upper lobes and small nodules are seen in the bilateral lower lobes.

Table 1 Summary of reported cases of Reversed Halo Sign

\begin{tabular}{|c|c|c|}
\hline Diagnosis & Number of patients (\%) & [Ref.] \\
\hline Bronchiolitis obliterans organizing pneumonia & 2 & [6] \\
\hline Sarcoidosis & 1 & [8] \\
\hline Cryptogenic organizing pneumonia & $6 / 31(19 \%)$ & [5] \\
\hline Paracoccidioidomycosis & 15/148 (10\%) & [10] \\
\hline Cryptogenic organizing pneumonia & $2 / 34(5.9 \%)$ & [7] \\
\hline Secondary organizing pneumonia (of 1 breast cancer and 1 rheumatoid arthritis patient) & $2 / 34(5.9 \%)$ & [7] \\
\hline Paracoccidioidomycosis & 15/77 (19\%) & [13] \\
\hline Lymphomatoid granulomatosis & 1 & [14] \\
\hline Tuberculosis & 1 & {$[15]$} \\
\hline Lipoid pneumonia & 1 & [16] \\
\hline Wegener's granulomatosis & 1 & {$[17]$} \\
\hline Zygomycosis & $7 / 37(19 \%)$ & [9] \\
\hline Invasive pulmonary aspergillosis & $1 / 132(<0.7 \%)$ & [9] \\
\hline Sarcoidosis & 1 & [18] \\
\hline Sarcoidosis & 1 & [19] \\
\hline Tuberculosis & 1 & {$[20]$} \\
\hline Cryptogenic organizing pneumonia & 1 & {$[21]$} \\
\hline Pneumocystis pneumonia & 1 & present \\
\hline
\end{tabular}


repair itself [2]. This process produces the GGO and consolidation findings that can be observed with HRCT.

In the case presented here, pathological findings showed an inflammatory infiltrate in the alveolar space, without a great amount of hemorrhage, and unassociated with organizing pneumonia. PCP and PCM have many pathological and biological similarities. Thus, the mechanism causing the reversed halo sign in the two diseases may be the same, possibly stemming from the host's immune response or the biological features of mycosis.

To our knowledge, PCP has never been reported in connection with the reversed halo sign. PCP occurs not only in patients with AIDS, but also in individuals with other malignant diseases; the radiological features of PCP differ depending on patients' exact medical histories [11]. For instance, patients with AIDS presented GGO without consolidation on CT [11]. However, patients with malignancy were likely to experience PCP with diffuse GGO with inhomogeneous distribution unrelated to secondary lobes, and consolidation with GGO [11]. Additionally, PCP with malignancy has been observed in conjunction with nodular infiltration [12]. Consolidation in HIV-negative patients may be associated with severe inflammation of the lung. In the case study presented here, the reversed halo sign with HIVPCP is induced by the special condition of the host's immune system; his underlying diseases, including NHL and HIV, are likely to have influenced the development of the disease. The HIV infection is also likely to have been responsible for the cystic lesions that remained after the reversed halo sign disappeared, though this characteristic is much more commonly observed in PCP patients with AIDS [2].

\section{Conclusions}

The reversed halo sign does not appear to be specific for COP, and may be seen in patients with any active infection. This is likely because there are a number of different mechanisms that can cause this characteristic pattern. In this case, the reversed halo sign is likely to have been found in association with PCP because of the patient's infection with HIV. Because the reversed halo sign can indicate different diseases that require very different treatments, physicians should not assume a diagnosis of COP whenever patients present with this trait.

\section{Consent}

Written informed consent was obtained from the patient for publication of this case report and any accompanying imagings. A copy of the written consent is available for review by the Editor-in-chief of this journal.

\section{Author details}

'Department of Respiratory Medicine, Nishi-Kobe Medical Center 5-7-1, Kojidai, Nishi-ku, Kobe, 651-2273 Japan. ${ }^{2}$ Department of Pathology, NishiKobe Medical Center 5-7-1, Kojidai, Nishi-ku, Kobe, 651-2273 Japan.

\section{Authors' contributions}

$\mathrm{HO}$ was in charge of the overall care of the patient, performed the literature search, compiled data and drafted the manuscript. KT, TS and Al provided intellectual input and revised the manuscript. $\mathrm{KH}$ has participated in the histological diagnosis of the case. All authors have read and approved the final manuscript.

\section{Authors' information}

Departments of ${ }^{1}$ Respiratory Medicine and ${ }^{2}$ Pathology, Nishi-Kobe Medical Center

5-7-1, Kojidai, Nishi-ku, Kobe, 651-2273 Japan

\section{Competing interests}

The authors declare that they have no competing interests.

Received: 23 July 2010 Accepted: 23 November 2010

Published: 23 November 2010

\section{References}

1. Thomas CF Jr, Limper AH: Pneumocystis pneumonia. New Engl J Med 2004, 350:2487-2498.

2. Kuhlman JE: Pneumocystic infections: The radiologist's perspective. Radiology 1996, 198:623-635.

3. Boiselle PM, Crans CA, Kaplan MA: The changing face of Pneumocystis carinii Pneumonia in AIDS patients. AJR 1999, 172:1301-1309.

4. Fujii T, Nakamura T, Iwamoto A: Pneumocystis pneumonia in patients with HIV infection: clinical manifestations, laboratory findings, and radiological features. J Infect Chemother 2007, 13:1-7.

5. Kim SJ, Lee KS, Ryu YH, Yoon YC, Choe KO, Kim TS, Sung KJ: Reversed halo sign on high-resolution $\mathrm{CT}$ of cryptogenic organizing pneumonia: diagnostic implications. AJR 2003, 180:1251-1254.

6. Voloudaki AE, Bouros DA, Froudarakis ME, Datseris GE, Apostolaki EG, Gourtsoyiannis NC: Crescentic and ring-shaped opacities. CT features in two cases of bronchiolitis obliterans organizing pneumonia (BOOP). Acta Radiol 1996, 37:889-892.

7. Soberón AB, Sánchez MIT, Rio FG, Almaraz CS, Pajares MP, Rodoíquez MP: High resolution computed tomography patterns of organizing pneumonia. Arch Bronchoneumol 2006, 42:413-416.

8. Marlow TJ, Krapiva PI, Schabel SI, Judson MA: The "fairy ring": a new radiographic findings in sarcoidosis. Chest 1999, 115:275-276.

9. Wahba H, Truong MT, Lei X, Kontoyiannis DP, Marom EM: Reversed Halo Sign in Invasive Pulmonary Fungal Infections. Clin Infect Dis 2008, 46:1733-1737.

10. Gasparetto EL, Escuissato DL, Davaus T, de Cerqueira Elza Maria FP, Souza AS Jr, Marchiori E, Müller NL: Reversed halo sign in pulmonary paracoccidioidomycosis. AJR 2005, 184:1932-1934.

11. Tasaka S, Tokuda H, Sakai F, Fujii T, Tateda K, Johkoh T, Ohmagari N, Ohta H, Araoka H, Kikuchi Y, Yasui M, Inuzuka K, Goto H: Comparison of Clinical and Radiological Features of Pneumocystis Pneumonia Between Malignancy cases and Acquired Immunodeficiency Syndrome Cases: A Multicenter Study. Inter Med 2010, 49:273-281.

12. Torres HA, Chemaly RF, Storey R, Aguilera EA, Nogueras GM, Safdar A, Rolston KVI, Raad II, Kontoyiannis DP: Influence of type of cancer and hematopoietic stem cell transplantation on clinical presentation of Pneumocystis jiroveci pneumonia in cancer patients. Eur J Clin Microbiol Infect Dis 2006, 25:382-388

13. Souza AS, Gasparetto EL, Davaus T, Escuissato DL, Marchiori E: HighResolution CT Findings of 77 Patients with Untreated Pulmonary Paracoccidioidomycosis. AJR 2006, 187:1248-1252.

14. Benamore RE, Weisbrod GL, Hwang DM, Bailey DJ, Pierre AF, Lazar NM, Maimon $\mathrm{N}$ : Reversed halo sign in lymphomatoid granulomatosis. $\mathrm{Br} J$ Radiol 2007, 80(956):e162-6.

15. Ahuja A, Gothi D, Joshi JM: A 15-year-Old Boy with "Reversed Hallo". Indian J Chest Dis Allied Sci 2007, 49:99-101. 
16. Kanaji N, Bandoh S, Nagamura N, Chang SS, Ishikawa S, Yokomise H, Katsuki N, Haba R, Kushida Y, Ishida T: Lipid pneumonia showing multiple pulmonary nodules and reversed halo sign. Respir Med Extra 2007, 3:98-101.

17. Agarwal R, Aggarwal AN, Gupta D: Another cause of reversed halo sign: Wegener's granulomatosis. Br J Radiol 2007, 80:849-850.

18. Kumazoe H, Matsunaga K, Nagata N, Komori M, Wakamatsu K, Kajiki A Nakazono T, Kudo S: "Reversed halo sign" of high-resolution computed tomography in pulmonary sarcoidosis. J Thorac Imaging 2009, 24:66-68.

19. Marchiori E, Zanetti G, Mano CM, Hochhegger B, Irion KL: The reversed halo sign: another atypical manifestation of sarcoidosis. Korean J Radiol 2010, 11:251-252.

20. Marchiori E, Grando RD, Simões Dos Santos CE, Maffazzioli Santos Balzan L, Zanetti G, Mano CM, Gutierrez RS: Pulmonary tuberculosis associated with the reversed halo sign on high-resolution CT. Br J Radiol 2010, 83:e58-60.

21. Maimon N: A 47-year-old female with shortness of breath and "reversed halo sign". Eur Respir Rev 2010, 19:83-85.

\section{Pre-publication history}

The pre-publication history for this paper can be accessed here: http://www.biomedcentral.com/1471-2342/10/26/prepub

doi:10.1186/1471-2342-10-26

Cite this article as: Otera et al:: Reversed halo sign in pneumocystis pneumonia: a case report. BMC Medical Imaging 2010 10:26.

\section{Submit your next manuscript to BioMed Central} and take full advantage of:

- Convenient online submission

- Thorough peer review

- No space constraints or color figure charges

- Immediate publication on acceptance

- Inclusion in PubMed, CAS, Scopus and Google Scholar

- Research which is freely available for redistribution

Submit your manuscript at www.biomedcentral.com/submit 